\title{
Building a Healthcare System for Obese Patients
}

\author{
${ }^{1}$ Ahmed Abdelgader Fadol Osman, ${ }^{2}$ Aouf Abdulrahman Al-Dabal, ${ }^{3}$ Fahad Mohammed Al-Buali \\ ${ }^{1}$ Assistant Professor, College of Computer Science and Information, Open University of the Sudan, Sudan and Imam Muhammad \\ bin Saud Islamic University, Saudi Arabia \\ ${ }^{2,3}$ Department of Computer Science and Information, College of Sharia and Islamic Studies at Al-Ahsa, Imam Muhammad bin \\ Saud Islamic University, Saudi Arabia
}

\begin{abstract}
Obesity has become one of the most common public health problems affecting people of both sexes according to the statistics of the World Health Organization in 2020, 39\% of adults aged 18 years and over were overweight in 2016, and $13 \%$ were obese (who, 2020). Being obese can increase your risk of developing many potentially serious health conditions [2]. Compounding this problem is the lack of awareness among people of its danger. Many studies proved that more than $65 \%$ of obese patients facing difficulty in communicating with Nutrition physician (Truswell, 2000) (Katja Mikhailovich, 2007) (Kathryn M. Kolasa, 2010) (TerrillBravender, 2013) (S M E van Dillen, 2008). therefore, The proposed system deal with this problem by designing a simple system contains effective feature such as live chat, to make communication between user and nutrition doctors easy and to and allow them to have a healthy lifestyle. In addition to helping increase awareness to avoid obesity. Eventually, the researchers implemented the system using PHP language for the backend of the website and using HTML, CSS, bootstrap, and JavaScript for frontend and MySQL for databases.
\end{abstract}

Keywords: health care systems; obesity; nutrition doctor; live chat, BMI, BMR.

\section{INTRODUCTION}

Overweight and obesity defined as abnormal or excessive fat accumulation that may impair health.

Body mass index (BMI) is a simple index of weight-forheight that commonly used to classify overweight and obesity in adults. It defined as a person's weight in kilograms divided by the square of his height in meters $(\mathrm{kg} / \mathrm{m} 2)[1]$. Obesity and overweight can increase the risk of several health conditions, including arthritis, metabolic syndrome, some types of cancer, high blood pressure, type 2 diabetes, and cardiovascular disease[8]. Most patients facing difficulties in consulting a nutritional doctor, most of them facing difficulty in knowing how to start a new healthier lifestyle. In addition to the low level of awareness among the society members about negative side effects of obesity. This issue causes a decrease in the level of health among society members.
Moreover, treatment recommendations for obesity based on BMI. The body mass index of $25 \mathrm{~kg} / \mathrm{m} 2$ is the generally accepted limit for determining which patient is most susceptible to obesity-related diseases; the risk of death begins to increase at a body mass index of $23 \mathrm{~kg} / \mathrm{m} 2$ when compared to the least dangerous group (body mass index, 19.0 to $21.9 \mathrm{~kg}$ / m2). Medical risks gradually increase with increasing degrees of obesity, starting with weight gain[9].

To determine whether a person has a weight appropriate for their age, gender, and height, the nutritionists used a special method called Body mass index (BMI) to combine height and weight.

If someone is in a range between 25 and 29.9 in BMI that indicates, he is overweight. A BMI of 30 or more indicates that a person may be obese.

Other factors play a main role in determining the degree of healthy a person's weight and body shape, like the waist-toheight ratio (WHR), the ratio of waist-to-hip size (WHR), Moreover, the distribution of fat on the body[10].It is very important to maintain a healthy weight, so peoples are encouraged to do exercise to lose weight, but sometimes they may have to go into major surgery.

Currently, the work proves that People with weight gain find it difficult to consult a nutritionist. After the diagnosis of the patient's condition and this procedure is either by the Health Nutrition Branch or by hospitals.

The researchers aim to create an online system that helps to educate people about good healthy habits to avoid obesity. This system contains a simple tool to determine if the user is overweight by calculating their body mass index (BMI) after that the system can select the appropriate procedure.

It contains live chat to make communication between users and nutrition doctor Easier and to give them a good opportunity to have a healthy lifestyle. Besides, helping in raising awareness to avoid obesity.

The people who use this system will find a positive impact on their lives. In the short term, it will help them to 
ISSN (online): 2581-3048

follow an appropriate diet, to build a strong and healthy body. In the long term, it helps to avoid many diseases that cause by obesity.

\section{RELATED WORK}

As in (webteb, 2019) this portal provides the latest information on nutrition, diet, pregnancy, and childbirth, child health, cancer, heart disease, diabetes, sex, and marriage. While the proposed application is specialized in avoiding obesity and determining if the patient needs to contact a nutrition doctor or if the patient needs to raise the awareness of a healthy.

In (sehhiya, 2020) the website is a health guide to losing weight, healthy eating, and dieting. Includes Delicious food and new pictures with nutritional information. Does not provide medical follow-up with patient, or live communication with the doctor. Not all its materials considered as medical advice or therapeutic recommendation.

while the proposed application Providing licensed content from established global organizations and academic institutions such as Mayo Clinic, Harvard Medical School, WHO, and National Health Service in the united kingdom

In (fitnessyard, 2018)the website care about fitness, bodybuilding and muscle building, exercise and information, tools, and tips to tighten the body and burn fat. Nevertheless, it considered a complex system.

while the proposed model is based on a general system that can be used easily, in addition to providing instructions on healthy food and dieting.

All previous solutions focused on providing medical information, advice, and calculating BMI. The proposed model classified users into three groups based on the calculation of BMI, after that appropriate service will be provided for each case including direct communication with the nutritionist.

\section{METHOD}

\section{a) Proposed Process}

The system built to receive some user's information such as age, height, and weight. After that, the system calculates the mass index BMI according to that the user classified within the following categories:

- Between 25.0 and $29.9 \mathrm{~kg} / \mathrm{m} 2$ normal

- Class I obesity (BMI, 30.0 to $34.9 \mathrm{~kg} / \mathrm{m} 2$ )

- Class II obesity (BMI, 35.0 to $39.9 \mathrm{~kg} / \mathrm{m} 2$ )

- Class III or extreme obesity (BMI $\geq 40 \mathrm{~kg} / \mathrm{m} 2)$ [14]
After that, the system selects the appropriate method for dealing with the case, if the user within the first or second class, by providing him medical instructions about following a specific diet. Or advising him to communicate directly with a nutritionist if he in class III.

\section{b) Proposed System Functional Requirements}

The proposed system includes the following requirements:

1. With regard to the doctor, the main requirements to be store in the database is the basic information, such as Doc. no, Doc.name, mobile number, number of medical staff; allow update of theses information and search permissions with different criteria.

2. With regard to the user, the requirements is the ability to store user's information including ID, name, gender, Weight, height, BMI, medical history.

\section{c) System Modelling}

System modeling is one of the basic processes of system development, where each model provides a different perspective of the system, using specific types of graphical symbols, using the Unified Modeling Language (UML) symbols. Which helps the system analyst to understand the functions of the system accurately and correctly; it used to communicate with customers and to confirm their requests (Booch, 1999).

\section{Activity diagram}

The researchers used the activities diagram to illustrate the progress that controlling the system and the relationship between it and the use case diagram. The graphs used to represent the sequential and concurrent activities of this system (Sommerville, 2011). The researchers essentially charted the workflow within the health system which clearly showing the activities and functions of the system, focusing on the flow and sequence state Events, which precisely describes the causes of a specific event and the reaction to that.

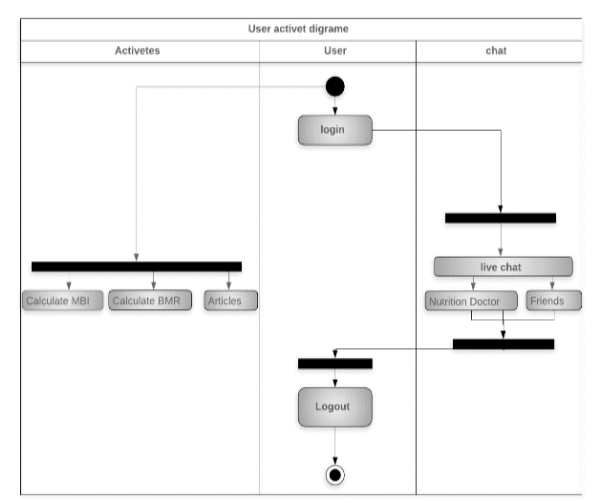

Figure 1: User activity diagram 
The Figure 1 shows the process of using the system, starting with making a choice, whether the user has an account to $\log$ in or make a new one; so, the system have five choices:

1. User, which use to create a new account, to communicate with doctor.

2. Calculate BMI to determine body mass index.

3. Calculate BMR to determine Basal metabolic rate.

4. Read articles and Recommendations.

5. Logout, which allow user to sign out.

\section{Class Diagram}

The class diagram bellow shows the system objects and their properties, beside clear definition for the operations of each object and the relations among them. The system consists of the following classes (visitor, user, doctor, and admin) as shown in figure (2).

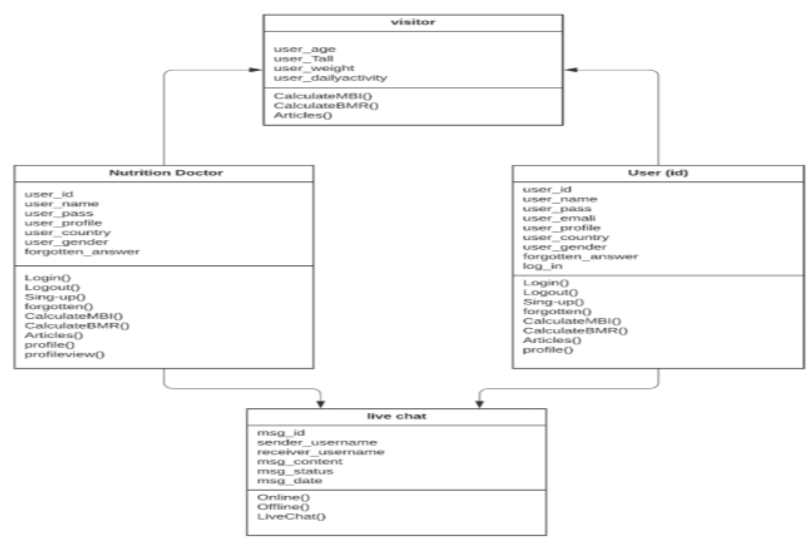

Figure 2: Class diagram

\section{Sequence Diagram}

A sequence diagram simply depicts interaction between system objects in a sequential order. The order in which these interactions take place. Sequence diagrams describe how and in what order the objects in a system function (Sommerville, 2011).

The diagram shows the order in which activities carried out in sequential order.

As shown in figure 3 the sequence diagram shows the system functionalities, which are:

1. Log in, allow user to access system.

2. Enter basic information.

3. Submit assessment.

4. Communicate with Dietician (via sms message or live chat).

5. Take Dietician's recommendations and treatments.

6. Determine next appointment.
7. Browse articles.

8. Logout, allow the user sign out of the system.

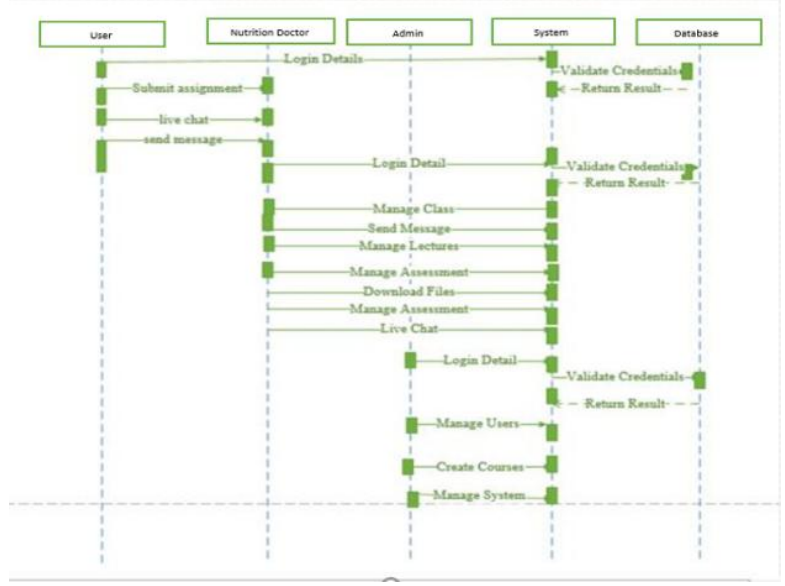

Figure 3: Sequence Diagrams

\section{d) Data Modelling}

\section{Entity Relationship diagram}

This figure shows the relationship between system entities. Entity Relationship (E-R) Model: Researchers used the entity relationship model (E-R) to design diagrams that help to understand the relationship (ERDs) among health system entities such as users, system administrator, and dietitian, also used to determine the needs and elucidate the characteristics of each of them separately[16], including the general structure and methods of interaction of different data types.

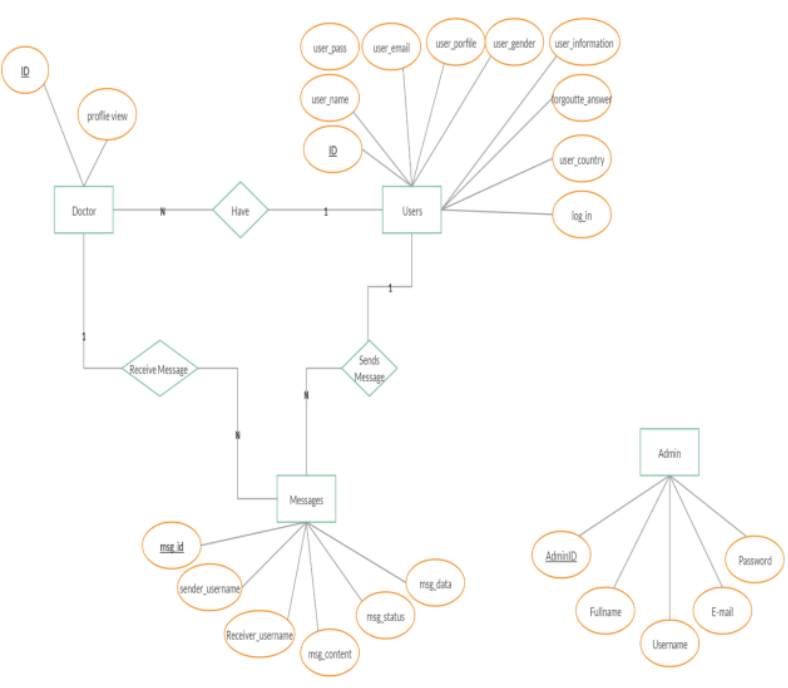

Figure 4: Entity Relationship Diagram

\section{Data Dictionary}

As shown in table1, the researcher designed the data dictionary to build the system database. 


\begin{tabular}{|c|c|c|}
\hline Users table & Data type (size) & Description \\
\hline user_id & Int (11) & $\begin{array}{l}\text { Primary key of } \\
\text { table }\end{array}$ \\
\hline user_name & Varchar (100) & Username \\
\hline user_pass & Varchar (100) & User password \\
\hline user_email & Varchar (100) & User email \\
\hline user_porfile & Varchar (255) & User information \\
\hline user_country & Text & Chose country \\
\hline user_gender & Text & $M=$ male,$F=$ female \\
\hline forgotten_answer & Varchar (100) & $\begin{array}{l}\text { To return user } \\
\text { password }\end{array}$ \\
\hline log_in & Varchar (7) & $\begin{array}{l}\text { Show state of user } \\
\text { (online, offline) }\end{array}$ \\
\hline Doctor table & $* * * * * * * * * * *$ & $* * * * * * * * * * * *$ \\
\hline Doc_id & Int (11) & $\begin{array}{lll}\begin{array}{l}\text { Primary key of } \\
\text { table }\end{array} & & \end{array}$ \\
\hline Doc_name & Int (11) & Username \\
\hline Doc_Medical ID & Int (11) & User password \\
\hline Doc_phone number & Int (11) & User information \\
\hline Doc_email & Varchar (100) & Doctor email \\
\hline view_proflie & Varchar (255) & User information \\
\hline
\end{tabular}

\section{e) Programming Language}

The project has been implemented through the PHP 7.4 language for the backend of the website and using HTML is a dynamic, high level, free open source and interpreted programming language. It supports object-oriented programming as well as procedural oriented programming. It has many features made the researchers choose it to implement the system. The researchers took advantage of these features in implementing the system. (team, 2019)In addition, to contact databases with live chat and link between interfaces and databases.CSS bootstrap, and JavaScript for frontend and MySQL for databases.

\section{f) System Requirements}

The system requires a computer, tablet or mobile device that has the ability to browse the Internet.

\section{SYSTEM TESTING}

a) Features to be tested: 1-The user signup for chat. 2-User sign in. 3-The user sing in for chat. 4-The user logs out of chat. 5-Calculate BMI. 6-Calculate BMR. 7-Profile the user. 8-Change account setting. 9-Forgotten the password.

b) Test Cases: Table II: Valid log in test case.

Table 2: The user signup for chat

\section{Component Diagram}

Schematic diagram of the proposed system components Figure 5 shows a diagram of the components that designed to help implement and determine the details of the model (Sommerville, 2011); in addition, researchers used it to verify that all required system functions covered as planned.

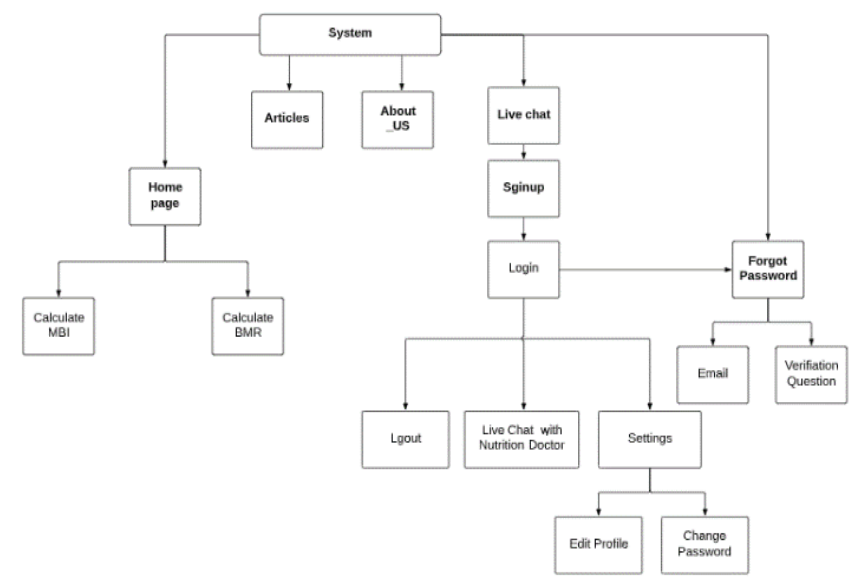

\begin{tabular}{|l|l|}
\hline \multicolumn{1}{|c|}{ Table 2: The user signup for chat } \\
\hline Test case name & Users sign up. \\
\hline Purpose & Create a Private account. \\
\hline Input & $\begin{array}{l}\text { E-mail, Password, Gender, country, } \\
\text { and User name. }\end{array}$ \\
\hline Expected Output & The account is done after validation. \\
\hline Test Result & The user can login. \\
\hline
\end{tabular}

Table 3: User sign in

\begin{tabular}{|l|l|}
\hline Test case number & \multicolumn{1}{|c|}{2} \\
\hline Test case name & User sign in. \\
\hline Purpose & $\begin{array}{l}\text { The user can participate in the } \\
\text { website. }\end{array}$ \\
\hline Input & E-mail, Password. \\
\hline Expected Output & The User sign in the website. \\
\hline Test Result & $\begin{array}{l}\text { The user can obtain knowledge, } \\
\text { benefit and enjoyment. }\end{array}$ \\
\hline
\end{tabular}

Figure 5: Component Diagram 
Table 4: The users sing in for chat

\begin{tabular}{|l|l|}
\hline Test case number & \multicolumn{1}{|c|}{3} \\
\hline Test case name & User sign out of chat. \\
\hline Purpose & $\begin{array}{l}\text { The user can sing out of chat in the } \\
\text { website. }\end{array}$ \\
\hline Input & Click the bottom. \\
\hline Expected Output & The User sign out of the website. \\
\hline Test Result & The user can be out of chat. \\
\hline
\end{tabular}

\begin{tabular}{|l|l|}
\hline \multicolumn{2}{|l}{ Table 5: Calculate BMI } \\
\hline Test case number & \multicolumn{1}{|c|}{4} \\
\hline Test case name & Calculate BMI. \\
\hline Purpose & $\begin{array}{l}\text { The user can calculate BMI in the } \\
\text { website. }\end{array}$ \\
\hline Input & Length and Wight. \\
\hline Expected Output & The User Weight Index Scale. \\
\hline & $\begin{array}{l}\text { The user can BMI beneath 18 } \rightarrow \\
\text { Underweight or between 18 to }- \\
\text { 18.5 } \rightarrow \text { Lean or thin for your } \\
\text { stature or between 18.5 to }-24.9 \rightarrow \\
\text { Healthy or between } 25 \text { to }-29.9 \\
\rightarrow \text { Overweight or over 30or above } \rightarrow \\
\text { Obese }\end{array}$ \\
\hline
\end{tabular}

\begin{tabular}{|l|l|}
\hline \multicolumn{1}{|c|}{ Table 6: Calculate BMR } \\
\hline Test case number & \multicolumn{1}{c|}{5} \\
\hline Test case name & User calculate BMR. \\
\hline Purpose & $\begin{array}{l}\text { The user can calculate BMR in the } \\
\text { website. }\end{array}$ \\
\hline Expected Output & $\begin{array}{l}\text { Gender, Age, Height, Weight and } \\
\text { Activity. }\end{array}$ \\
\hline Test Result & $\begin{array}{l}\text { Burning calories. } \\
\text { carb, protein and fat can burn per } \\
\text { day. }\end{array}$ \\
\hline
\end{tabular}

\begin{tabular}{|l|l|}
\hline \multicolumn{2}{|c|}{ Table 7: Profile of user } \\
\hline Test case number & 6 \\
\hline Test case name & Profile the user. \\
\hline Purpose & $\begin{array}{l}\text { The user can create profile in } \\
\text { the website. }\end{array}$ \\
\hline Input & $\begin{array}{l}\text { Name, country, picture and } \\
\text { Gender. }\end{array}$ \\
\hline Expected Output & Show profile. \\
\hline
\end{tabular}

https://doi.org/10.47001/IRJIET/2020.408003

\begin{tabular}{|l|l|}
\hline Test Result & $\begin{array}{l}\text { The user can kwon other user } \\
\text { profile. }\end{array}$ \\
\hline
\end{tabular}

Table 8: Change account setting

\begin{tabular}{|c|c|}
\hline Test case number & 7 \\
\hline Test case name & Change account setting. \\
\hline Purpose & $\begin{array}{l}\text { The user can change the profile } \\
\text { in the website. }\end{array}$ \\
\hline Input & $\begin{array}{l}\text { E-mail, forgotten password, } \\
\text { Gender, country, change } \\
\text { password and Username. }\end{array}$ \\
\hline Expected Output & Change profile. \\
\hline Test Result & $\begin{array}{l}\text { The user can change user } \\
\text { profile. }\end{array}$ \\
\hline
\end{tabular}

Table 9: Forgotten the password

\begin{tabular}{|l|l|}
\hline Test case number & \multicolumn{1}{|c|}{8} \\
\hline Test case name & Forgotten the password. \\
\hline Purpose & $\begin{array}{l}\text { The user can create profile in } \\
\text { the website. }\end{array}$ \\
\hline Input & $\begin{array}{l}\text { User E-mail and Conform } \\
\text { question. }\end{array}$ \\
\hline Expected Output & Return password. \\
\hline Test Result & $\begin{array}{l}\text { The user can kwon the } \\
\text { password. }\end{array}$ \\
\hline
\end{tabular}

\section{RESULT AND DISCUSSION}

As a result, a system established to guide obese people to healthy lifestyle, including those with chronic diseases, based on WHO standards, which fulfills its functions as mentioned below. When the system starts up, the main screen appears as in Figure (6), which shows the main features of the system.

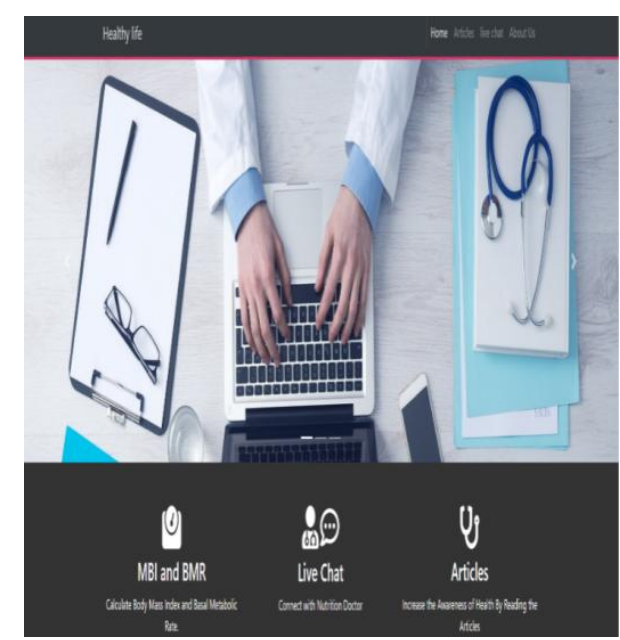

Figure 6: System Interfaces 
Figure 7 explain how the system calculates BMI accurately, depending on height and weight.

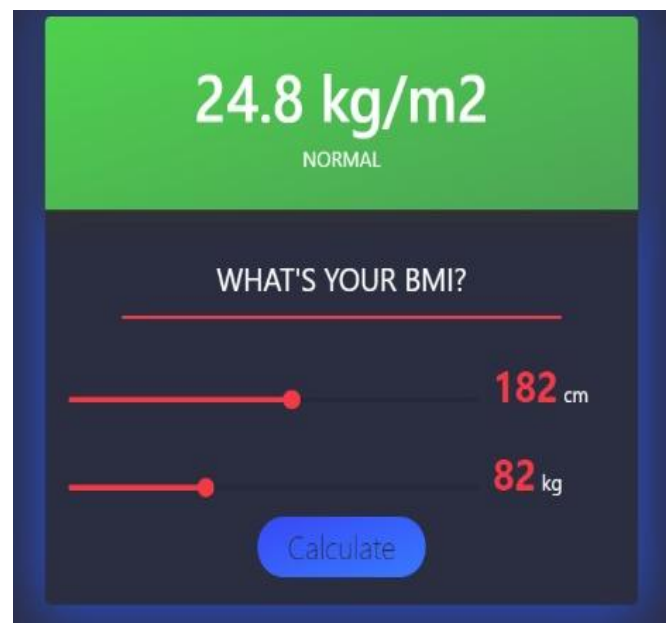

Figure 7: BMI Calculator

Figure 8 show BMR calculator, user have to enter his information such as age, height, weight and activity which is used by the system to calculate BMR

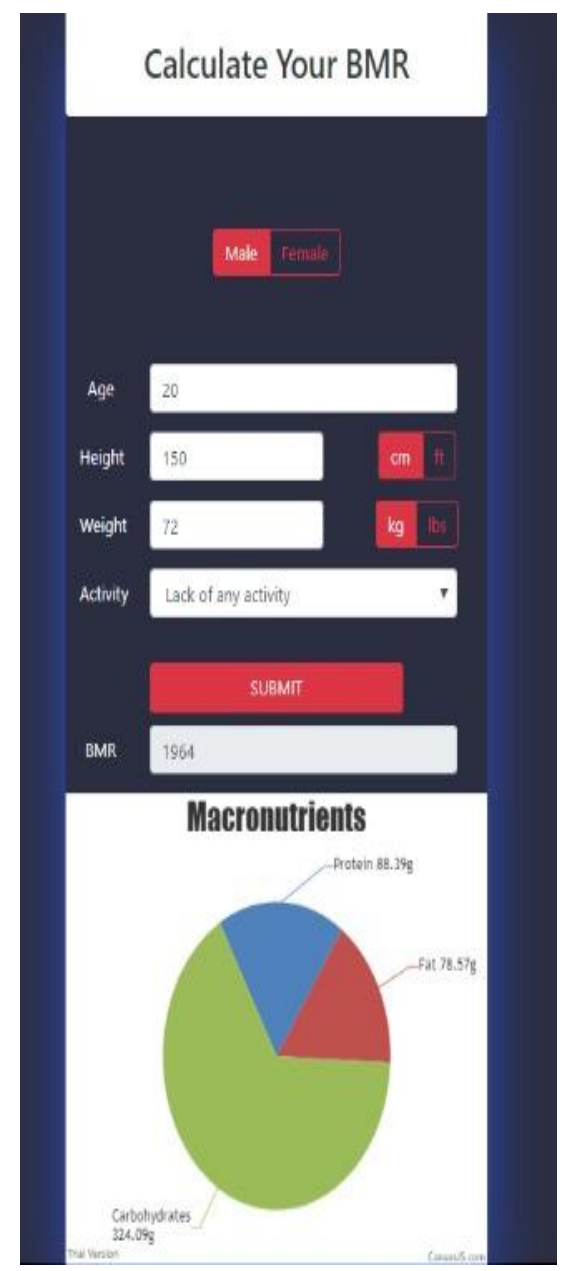

Figure 8: BMR calculator

Figure 9 show live chat between user and doctor.

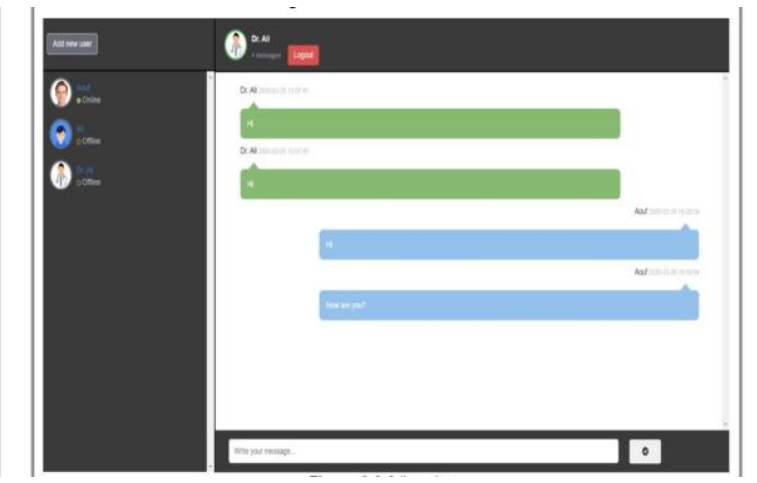

Figure 9: Live chat

Figure 10 show articles section, which is contain recommended treatments and diet programs, beside some articles To help users avoid weight gain.

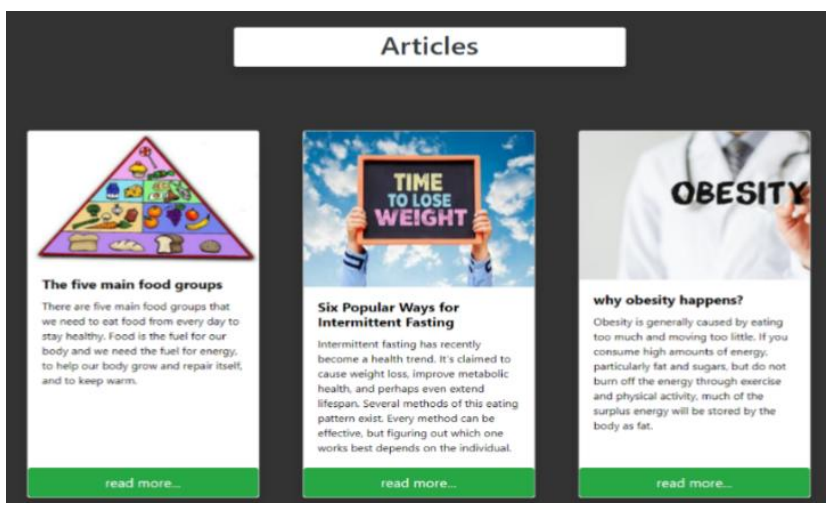

Figure 10: Articles section

\section{CONCLUSION}

This system built depending on WHO standers. Moreover, it implemented using PHP, HTML, CSS, bootstrap, and JavaScript for frontend and MySQL for databases. This system offers benefits for people who want to follow a lifestyle. It aims to determine whether the user is Obese or not by calculating his/her body mass index (BMI), Basal Metabolic Rate (BMR) and, then, to decide if the user needs to contact a nutrition doctor or to raise his/her awareness about a healthy lifestyle, depending on the results of the body mass index.

\section{REFERENCES}

[1] "who," World Health Organization, 142020. [Online]. Available: https://www.who.int/newsroom/fact-sheets/detail/obesity-and-overweight. [Accessed 157 2020].

[2] "nhs," 16, 5, 2019. [Online]. Available: https://www.nhs.uk/conditions/obesity/\#: :text=Bein g\%20obese $\% 20$ can $\% 20$ also $\% 20$ increase, coronary $\% 2$ Oheart $\% 20$ disease $\% 20$ and $\% 20$ stroke. [Accessed 107 2020]. 
ISSN (online): 2581-3048

[3] A.S.Truswell, "Family physicians and patients: is effective nutrition interaction possible?," American Society for Clinical Nutrition, vol. 71, no. 1, pp. 612, 2000.

[4] P.M.Katja Mikhailovich, "Discussing childhood overweight and obesity with parents: a health communication dilemma," Journal of Child Health Care, vol. 11, no. 4, pp. 311-322, 2007.

[5] K.R.Kathryn M. Kolasa, "Barriers to Providing Nutrition Counseling Cited by Physicians," NUTRITION in clinical practice, vol. 25 , no. 5 , pp. 502-509, 2010.

[6] J. A. D. S. C. J. J. A. P.-H. I. Terrill Bravender, "Teen CHAT: Development and utilization of a webbased intervention to improve physician communication with adolescents about healthy weight," Patient Education and Counseling, vol. 93, no. 3, pp. 525-531, 2013.

[7] G. J. H. A. N. S M E van Dillen, "A comparison of Dutch family doctors' and patients' perspectives on nutrition communication," Family Practice, vol. 25, no. 1, p. 87-92, 2008.

[8] C. M. Phillips, "Metabolically healthy obesity: Definitions, determinants and clinical implications," Reviews in Endocrine and Metabolic Disorders, vol. 14, pp. 219-227, 2013.

[9] W. Z. N. B. Z. A. C. L. B. \&. A. H. A. Daphne P Guh, "The incidence of co-morbidities related to obesity and overweight: A systematic review and meta-analysis," BMC Public Health, vol. 9, no. 88, 2009.

[10] Z.-R. C. J.-N. C. Y.-H. L. a. J. C. Rui-Dan Zheng, "Role of Body Mass Index, Waist-to-Height and Waist-to-Hip Ratio," Hindawi Publishing Corporation, vol. 2012, no. 362147, 2012.

[11] webteb, "webteb," webteb company, 112019. [Online]. Available: https://www.webteb.com/. [Accessed 6 may 2020].

[12] sehhiya, "sehhiya," 1 may 2020. [Online]. Available: http://sehhiya.com. [Accessed 12 may 2020].

[13] fitnessyard, "fitnessyard," fitnessyard, 14 january 2018. [Online]. Available: https://en.fitnessyard.com/. [Accessed 7 january 2020].

[14] G. R. J. a. J. I. Booch, The Unified Modeling Language User Guide, vol. 42, Massachusetts: Addison Wesley, 1999.
[15] I.Sommerville, SOFTWARE ENGINEERING, Boston: Addison-Wesley, 2011.

[16] Marcela Generoa Geert Poelsb Mario Piattinia, "Defining and validating metrics for assessing the understandability of entity-relationship diagrams," Data \& Knowledge Engineering, vol. 64, no. 3, pp. 534-557, 2008.

[17] T.P.d.team, "PHP," PHP Group, 31 October 2019. [Online]. Available: https://www.php.net/releases/7_4_0.php. [Accessed 2 may 2020].

[18] m.center, "meadia center portal," 157 2020. [Online]. Available: https://www.moh.gov.sa/Ministry/About/Health\%20 Policies/008.pdf.

[19] D. C. Y. J. A. R. R. M. D. JAMES M. LYZNICKI, "Obesity: Assessment and Management in Primary Care," American family physician, vol. 63, no. 11, p. 2185, 2001.

[20] L. J. Aronne, "Epidemiology, morbidity, and treatment of overweight and obesity." The Journal of clinical psychiatry, vol. 62, no. 23, p. 13, 2001.

\section{AUTHOR'S BIOGRAPHIES}

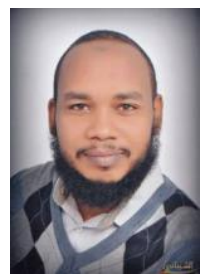

Dr. Ahmed Abdelgader Fadol Osman, Assistant professor in computer science. Open university of Sudan. Imam Mohammed ibn Saud Islamic university.

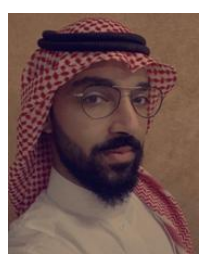

Aouf Abdulrahman Al-Dabal, Bachelor of Computer Science

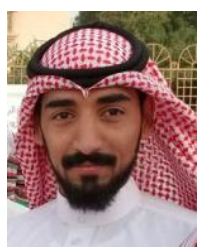

Fahad Mohammed Al-Buali, Bachelor of Computer Science 
Citation of this Article:

Ahmed Abdelgader Fadol Osman, Aouf Abdulrahman Al-Dabal, Fahad Mohammed Al-Buali, "Building a Healthcare System for Obese Patients" Published in International Research Journal of Innovations in Engineering and Technology IRJIET, Volume 4, Issue 8, pp 12-19, August 2020. https://doi.org/10.47001/IRJIET/2020.408003 